INTERNATIONAL JOURNAL OF MULTidisciplinARY RESEARCH AND ANALYSis

ISSN(print): 2643-9840, ISSN(online): 2643-9875

Volume 04 Issue 01 January 2021

DOI: 10.47191/ijmra/v4-i1-01, Impact Factor: 5.522

Page No.- 01-10

\title{
The Effect of Selected Socio-Economic Determinants of Health on Maternal/ Child Health in Nigeria
}

\author{
Atayi Abraham Vincent ${ }^{1}$, Jirbo Boniface Verr ${ }^{2}$, Maji lliya ${ }^{3}$ \\ 1,2,3 Department of Economics, Faculty of Social and Management Science, Afe Babalola University, Ado Ekiti, Nigeria
}

ABSTRACT: The research examines the effect of socio-economic determinants of health on maternal / child health in Nigeria. Some level of improvement has been seen in every part of the world, while maternal mortality rates remain unacceptably high in Nigeria. This qualitative study was conducted in order to examine selected socioeconomic determinants of health and ways of dealing with mechanisms for improving maternal / child health among Nigerian women. A narrative literature review design was implemented using a variety of search engines that use a Boolean search technique to retrieve research publications. In the study, selected socio-economic health determinants that adversely affect maternal / child health were recognized. The determinants chosen include the health care provider's attitude, economic/financial inequality, regional (transport issues), vulnerability, marital status and age, education, gender equality, material and human capital, socio-cultural factors, and health care system delivery. Whereas good footwear, good dependency on social networks, education in maternal/child health, gender equity and involvement of men in reproductive health activities have been found to be common strategies for addressing maternal health services.

KEYWORDS: socio-economic determinants, child health, maternal/child, Nigeria

\section{INTRODUCTION}

The concept of maternal/child health has everything to do with the process of giving birth or better put, the process of reproducing another live. The issue of maternal / child health relates to the mother / child's reproductive health. In the view of (Glasier et al., 2006), in all matters relating to the reproductive system and its roles and mechanisms, reproductive health is a state of full physical , mental and social well-being, and not merely the absence of illness or infirmity. Reproductive health therefore implies the option of people to satisfy healthy sex lives that allows them to reproduce and determine when and how to do so (Glasier et al., 2006), In the opinion of the World Health Organization (WHO, 2004), the 10th revision of the International Statistical Classification of Diseases (ICD, 2010) and Related Health Problems Maternal mortality is characterized as the death of a woman while pregnant or within 42 days of termination of pregnancy, irrespective of the length and location of pregnancy, of any cause related to or exacerbated by pregnancies. Nigeria, with its ever-growing population characterized by poverty, increased unemployment, political unrest, ethno-religious crisis, as well as natural or man-made disasters such as kidnapping, extremism and so on, are some of the major challenges facing Nigeria, which is also responsible for the high maternal / child health deterioration. Nigerian women need to be provided with education and jobs in order to improve maternal and child health.

Socio-economic status, cultural beliefs and norms are closely linked to maternal / child death or disability due to pregnancy and childbirth. Generally speaking, the geographical distance, vulnerability and marginalization of poor women are some of the risk factors for maternal and child health decline (Elias, 2018). Maternal / child deaths are higher in Nigeria due to less skilled and trained traditional birth attendants (TTBAs), less educated and poor women are vulnerable to maternal death and disability. High maternal mortality rates indicate poorly developed and working health care systems and deeply entrenched gender disparities that leave women with less influence, limited resource control, weak decision-making, limited access to socio-economic support and health services (Elias 2018).

In early life, gender differences are generally manifested. Girls born to poor families are more vulnerable to child marriage and abuse (UNFPA, 2012). The significance of the study on socio-economic determinants of maternal / child health among Nigerian women is crucial in addressing the determinants, developing coping mechanisms and identifying the gap in developing further strategies to help reduce the rate of maternal mortality The reality is that Nigeria's socio-economic determinants of maternal / child health are very broad and are more likely to be affected by policy, community context and geographic access, family features, 


\section{The Effect of Selected Socio-Economic Determinants of Health on Maternal/ Child Health in Nigeria}

cultural and social values, services of maternal / child health care and characteristics of maternal / child. Based on the sustainable development goals, (2015-2030), socio-economic determinants to maternal / child health among African countries especially Nigeria were seem to be a major concern of the global world. One of the main global health issues of growing concern is the phenomenon of socio-economic determinants of maternal / child health in Nigeria. Although the decrease in the maternal/child mortality rate has shown progress, it remains unacceptably high in Sub-Saharan Africa, especially Nigeria (UNICEF, 2016). The aim of this study is to examine the impact of socio-economic health determinants on maternal/child health in Nigeria, as well as the issues associated with them and ways in which they handle those socio-economic determinants.

\section{MATERNAL/CHILD HEALTH SERVICES IN NIGERIA}

The traditional African culture has largely affected women and their health, in the opinion of (Okeke et al., 2016). Various inequities toward women are being committed due to the patriarchal existence of most of these African communities. "It is not only what is done to women, but what is not done for them" (Okeke et al., 2016). According to the World Health Organization, maternal / child health (WHO, 2007) is characterized as a state of complete physical, mental and social well-being and not just the absence of disease or infirmity in all issues related to women's reproductive age. In addition, maternal health would include the ability to "exercise reproductive rights of family planning and access to basic focused prenatal care without the burden of patriarchy" with particularity to African societies, Maternal/child health services provide a wide variety of health services that mothers are provided before pregnancy, during pregnancy, childbirth and post-natal. Financial or geographical inhibitions that impair their overall health '(Okeke et al., 2016) consequently, maternal health care services include pre-natal care, childbirth and postnatal care. In addition, such cultural traditions continue to impact maternal / child health in Nigeria and other parts of African societies.

Women are not permitted to come out during such festivals, in the opinion of (Nwokocha, 2008) among Ibani people of Rivers State, as doing so would lead to severe punishment, not minding her health condition even when she is pregnant. Furthermore, in the northern part of the country where the purdah method is followed, the movement of women is somehow regulated to prevent them from being seen by other men besides their husbands. This has ramifications for their maternal / child welfare, as some would frown at male health practitioners who attend during delivery to their wife. Female health professionals would have to attend to them instead. Another cultural activity that affects women's freedom of movement, especially during emergencies, is the Yoruba Oro festival in the southern part of Nigeria.

The poor state of infrastructure, systemic failure and inability to access health services, particularly for rural dwellers, are another problem affecting maternal/child health in Nigeria. Bad organization and inability to access maternal/child health facilities is the biggest problem facing pregnant and nursing women in Nigeria. In Nigeria, maternity / child health care is divided into three phases, namely the levels of primary, secondary and tertiary care (Omo et al., 2010). Primary health centres are located in all Nigeria's 774 local government areas. In the primary health centres closest to them, pregnant women are expected to receive prenatal care, delivery and postnatal care. In the case of pregnancy difficulties they are directed to secondary treatment centers under the administration of the state government or tertiary centers operated by the federal government in the case of pregnancy issues (Omo et al., 2010).

Pregnancy-related death is the most important health concern faced by medical practitioners and Nigerians, according to (Akokuwebe and Okafor, 2015). Many of the Nigerian population are constantly on the verge of becoming victims of maternal mortality, particularly women with low socioeconomic backgrounds. This condition makes them vulnerable to illness, infirmity and, in most cases, causes death because of their inability to access good health care, especially reproductive health care. It is necessary for women to have unhindered access to quality reproductive health services in their reproductive age and to be empowered to make decisions on family planning issues (Akokuwebe and Okafor, 2015). Having unhindered access to comprehensive reproductive health care would increase the chances of women surviving during pregnancy, giving them the ability to have healthy children and enabling them to live. Nigeria's health care system, however, is rife with the difficulties of delivering quality facilities, poor employee attitudes to patients, lack of skills, lack of or poor equipment, and shortages of vital medicines. The unstable and epileptic energy (electricity) and the supply of water and the health sector as a whole are in a comatose condition. Nigeria's healthcare system is ranked 187th out of 190 member states of the United Nations (WHO, 2018).

According to a report conducted in 2003, it was shown that only 4.2 percent of Nigeria's public facilities have internationally appropriate requirements for essential obstetric treatment (Harrison, 2009). Nearly two-thirds of all women in Nigeria work outside of health facilities and without present medically trained attendants (Mojekwu and Ibekwe, 2012). The bad outcome of Nigerian health care is not unrelated to bad leadership and weak governance of the country. The essence of the political system in Kleptomania is at its height, with a high degree of impunity, profoundly rooted corruption, making development goals that include ensuring quality and affordable health for Nigerian people inconclusive.

IJMRA, Volume 4 Issue 01 January 2021

www.ijmra.in

Page 2 


\section{The Effect of Selected Socio-Economic Determinants of Health on Maternal/ Child Health in Nigeria \\ METHODOLOGY}

The study applied a narrative analysis design to a qualitative documentary study based on the effect of selected socio-economic determinants of health on maternal / child health in Nigeria on the socio-economic determinants associated with maternal / child health in Nigeria. Sources of data included: relevant academic papers, government service assessment studies, foreign agencies (WHO, UNFPA, Commission of the African Union) and non-governmental studies, documentation and unpublished works on the effect of socio-economic determinants on maternal and child health in Nigeria. Document searches were facilitated by the use of search engines such as PubMed, The Lancet, Google Scholar and internet-based public access domains, using a sampling strategy. Boolean search strategy and "grey-literature" (unpublished reports) were applied to retrieve relevant research publications. "Nigeria" AND "socio-economic determinants" OR "maternal / child wellbeing" AND / OR "maternal mortality" were the search words used. By revising the reference lists of retrieved publications which were applicable to the research, additional literature was obtained.

\section{LITERATURE REVIEW}

\section{Conceptual literature}

The health-seeking behavior model by Andersen and Newman (1973) tells the conceptual literature used in this research. As the foundation for health care programs, this indicates three theories. The first theory indicates that individuals' predisposing or socio-demographic features impact the individual's underlying penchant for seeking medical treatment. Therefore, it is fair that individuals of similar socio-demographic backgrounds pursue health care fairly. Therefore, predisposing factors such as age at birth, education, household size , number of prior pregnancies, and health-related characteristics will influence the use of maternal / child health services (Fosu, 1994).

"The second position is based on the" hypothesis of accessibility. This means that access to health care facilities and staff is also an equally significant determinant of the use of maternal / child health care. This suggests that the provision of such health facilities and the means of accessing these facilities can affect the desire of people to make use of health care services. The enabling factors, according to Fosu (1994), reflect the fact that certain families must have some means to obtain them, even if they are predisposed to use health services; that is, income, access, and availability of health services. A number of studies have shown that greater use of health services and improvement in health conditions is a significant determinant of accessibility (Chakraborty et al., 2003; Mekonnen and Mekonnen, 2003).

The third hypothesis indicates that the use of maternal / child health services may be impacted by the understanding of the value of modern health care services by the mother. The viewpoint on the use of maternal / child health services indicates that not only the presence of physical illness, but also the cultural understanding of disease decide medical need (World Bank, 1994; Orley, 1980; Maclean, 1976). The presumption underlying this position is that individuals may attribute minimal severity to certain health conditions because, based on their cultural understanding and experience of that condition, they may consider those conditions to be common (Azevedo et al., 1991; Buckley, 1976). Andersen and Newman (1973) claim that the most immediate cause of health care is the need factor. For a mother to pursue health care, the existence of predisposing and facilitating components may not be enough. She must consider the condition as extreme and assume that the desired benefits will be given by the treatment (Fosu, 1994). Therefore, data on the individual characteristics and accessibility of the population under consideration as well as their perception of morbidity which need to be analyzed in the identification of measures for the study of determinants of the use of health services, such as maternal health services.

\section{EMPIRICAL LITERATURE ON MATERNAL/CHILD HEALTH SERVICES}

Previous longitudinal studies have found that the use of maternal / child health services is linked to demographic, cultural and socio-economic factors, such as women's age, birth order, household size, education, ethnicity, place of residence, religious background, marital status, employment, level of income and accessibility. The current age of women is assumed to be an significant determinant of maternal / child health care services (Elo, 1992; Fosu, 1994). The age of the mother may be used as a proxy for the cumulative perception of health care services by mothers, which could have a positive effect on the use of health services. However, it may be argued that younger women could have an improved awareness of modern health care services and place more emphasis on modern medicine due to the advancement of modern medicine and the increase of educational opportunities for women in recent years. The opinion that older women are more likely to seek maternal / child health services than younger women is backed by a variety of studies (Addai, 2000; Chakraborty et al., 2003; Mekonnen and Mekonnen, 2003). Family size is another significant consideration for maternal / child health care programs. It is argued that because of so many demands on their attention, women from large families tend to under-use different maternal / child health care services. Larger families also have financial limitations that have a negative impact on health care facilities (Wong et al., 1987; Chakraborty et al., 


\section{The Effect of Selected Socio-Economic Determinants of Health on Maternal/ Child Health in Nigeria}

2003) and have found a U-shaped association between family size and the use of health services to address any pregnancy complications.

A model for determinants of maternal / child health care could clearly be endogenous in the size of the family (number of children). In such a case, as an instrument, birth form (single birth or first of multiple birth) could be used. This is confirmed by many studies that have identified a correlation between maternal / child health services and twin births. The basic point made is that compared to single birth, twin births are comparatively linked to more complications (Mohammadi et al., 1997; Hajian, 2000) and thus, compared to a single birth scenario, mothers may be likely to seek maternal / child health services. It is well known that the increased use of modern health care facilities is correlated with higher levels of family income (Elo, 1992; Fosu, 1994). The role of women in gainful jobs is also a significant factor that has a positive effect on the use of quality medical services to treat complications. This also encourages women to take part in the family's health care decision-making processes. Women who are interested in gainful jobs are more likely to use modern health care facilities during their pregnancy to treat complications (Chakraborty et al., 2003; Celik and Hotchkiss, 2000 ) showed that household income is positively and significantly correlated with the choice of delivery health facility. (Gage, 2007) also found that the use of maternal health care was negatively linked to household poverty and personal issues. The degree of learning of the mother has a major effect on the use of maternal health services (Elo, 1992).

It is said that education increases female autonomy so that women gain greater confidence and the ability to make decisions about their own wellbeing (Raghupathy, 1996). Skilled women are more likely to pursue higher quality treatment and have greater capacity to use health care inputs to deliver better care. It is argued that better educated women are more aware of health issues, are more aware of the availability of health care services, and are more successful in maintaining or gaining good health status by using this knowledge. There has been a positive association between the level of education of women and the use of maternal health services in a number of studies (Celik and Hotchkiss, 2000; Addai, 2000; Mekonnen and Mekonnen, 2003; Chakraborty et al., 2003). According to Gage (2007), social networks can provide women with access to contacts and knowledge on healthy motherhood in high school areas and minimize confusion about formal health systems.

Another aspect that can influence the use of maternal / child health services is the place of residence (rural or urban). Urban dwellers may be comparatively closer to health care facilities in most developed countries than their rural counterparts, raising the gap for rural dwellers from home to health facilities compared to those living in urban centres. (Stock, 1983) has shown that the physical proximity of healthcare facilities plays an important role in the usage of these facilities, especially in the context of developing countries. (Rahaman et al., 1982) found, for example, that geographical distance is one of Bangladesh's most significant determinants of the use of health care facilities in rural areas. The place of residence was found to be an significant variable for use (Navaneetham and Dharmalingam, 2002) in that women living in urban areas were found to be dominant in urban culture, with more pressure to act in ways viewed as "modern." Another factor that can impact the use of maternal / child health services is also the geographical area. Regions and provinces can have a varying share of national resources in many developing countries. In such circumstances, different geographic regions may be equipped differently with health care infrastructure and personnel, thereby influencing access and use. Addai's research on the determinants of the use of maternal-child health services in rural Ghana showed that the probability of consulting a doctor for prenatal care among rural residents increased while residing in the western and central regions. He also found that women living in rural areas of the western and central regions were twice as likely to see a doctor for prenatal care compared to the northern and upper regions. He clarified that this could be due to the ease of access among women living in rural areas of the western and central regions to health facilities and workers. Other variables reported in empirical research as having a major impact on the use of maternal health services are religious values and practices.

A Zimbabwean study (Van et al., 1999) found that women belonging to those religious groups were more likely to refrain from the use of prenatal care; John Morange Apostolic, Christ Church and Mugodhi. Similar studies have shown that religion is a major determinant of the use of maternal / child health care (Nwakoby, 1991; Nhindiri et al., 1995). Findings from (Addai, 2000; Navaneetham and Dharmalingam, 2002) highlight that faith and associated socio-cultural values and orientations have a major effect on the actions of women seeking antenatal health care. Via what (Andersen and Newman, 1973) refer to as the sense of need, religion can work. In that religious beliefs can moderate the expectations of women of need and seriousness of conditions of morbidity and therefore the willingness to seek remedies for treatment. Ethnicity is also another factor defined as affecting the use of maternal / child health care services by prior empirical studies (Elo, 1992; Gobindasamy and Ramesh, 1997; Matsumura and Gubhaju, 2001). Different ethnic groups may have distinct traditions, beliefs, and belief structures that can undoubtedly influence actions and interpretation, as well as the use of health services.

Ethnicity (Ekman et al., 2007) was established in Vietnam as a strong and robust factor affecting the use of maternal health care. They concluded from their findings that belonging to the ethnic majority community influences the usage of service 


\section{The Effect of Selected Socio-Economic Determinants of Health on Maternal/ Child Health in Nigeria}

in a substantial positive way. The above analysis of the literature shows that the use of maternal / child health services is greatly affected by cultural, religious, social, demographic and economic factors. In order to add to the current empirical literature and other maternal / child health services that have been omitted in previous empirical studies in Nigeria, this research aims to investigate the effect of selected socio-economic determinants of health on maternal / child health in the sense of this observation.

\section{EFFECT OF SOCIO-ECONOMIC DETERMINANTS OF HEALTH ON MATERNAL/CHILD HEALTH IN NIGERIA. Health Service Provider Attitude}

Reports from numerous studies have shown that poorly addressed healthcare providers, using blunt and critical language, have been observed to deter women from accessing healthcare services in Africa, especially Nigeria. A study in Kenya found that most health professionals had a bad attitude towards pregnant women, primarily female health care providers (Essendi et al., 2011; Ditekemena et al., 2012). Another study from Uganda also reported mistrust of health care providers due to unpleasant past experiences, fear of retribution and fear of being diagnosed with HIV infection as a determinants not attending at the health facilities (Cham and Sundby, 2005; Chi and Urdal, 2018).

\section{Economic / Financial Inequity}

The time, place and person, which means when, where and by whom you get the service, is determined by economic or financial wealth. Socio-economic status defines decision-making because without having money, a supportive husband, family, or social network, it is difficult. Therefore, if the service is unaffordable, unemployment, poverty, lack of cash to pay for transport are obstacles to decision-making on the use of health care services (Ochako et al., 2011; Babalola and Fatusi, 2009, Samb and Ridde, 2018) in the case of Nigeria.

\section{Geographical (Transportation Problems)}

The difficulties of the road network, poor physical access and infrastructure within the communities are shown by many studies as the main problems facing most residents of rural communities in the use of maternal / child health care in Nigeria. Therefore, the use of maternal / child health care was found to be greater in urban areas rather than in Ghana's rural areas (Essendi et al., 2011; Cham et al., 2005; Ochako et al., 2011; Babalola and Fatusi, 2009; and Mpembeni et al., 2007) Insecurity

In accessing maternal / child health services, protection and freedom of movement even during the night is decisive because security and safety is critical at all times when most of the obstetric cases or delivering mothers came to the health facility. Nigeria is in an emergency state in the event of insecurity. For example, the rise in the rate of kidnapping for ransom. Insecurity leads to loss of property, death, and disabilities, particularly during the night.(Essendi et al . , 2011; Chi and Urdal, 2018; Ochako et al . 2011).

\section{Marital Status and Age}

Maternal / child health was strongly affected by age, marital status and family size. Especially in the case of Nigerian women with large families to take care of. Some mothers are very busy with household tasks and are discouraged from going out for follow-up to health facilities (Chi et al., 2015; Ochako et al . , 2011; Babalola and Fatusi, 2009)

\section{Education}

Different studies in most African countries most especially Nigeria reported that formal education and health education as a selected socio-economic determinants of health has impact on maternal/child health because health seeking behavior of mothers depend on formal education and specifically health education at an individual and community level through regular health promotion activities (Ochako et al., 2011; Babalola and Fatusi, 2009; Gebremariam, 2007; Alvarez et al., 2009 and Chol et al., 2018) A study by Ditekemena, et al.,2012 reported males who were educated and with high income were seeking a good health care services for their wives/ women and children.

\section{Gender Equity}

One of the major facilitators for the utilization and access to maternal/child health services was found to be gender equality (Mpembeni et al., 2007 and Alvarez et al., 2009)

\section{Material and Human Resources}

There is a study that reported poor quality of maternal/child health care resulted from barriers that include lack of ultrasound machines, short clinic opening hours, and shortage of healthcare workers (Alvarez et al., 2009).

\section{Socio-cultural Factors}

Among the deep-rooted determinants that adversely influence maternal health are bad cultural values, habits and behaviors. These socio-economic factors also influence the communication of men in the community, especially those who 


\section{The Effect of Selected Socio-Economic Determinants of Health on Maternal/ Child Health in Nigeria}

accompany their wives to the health facility, as if they are dominated by their wives (Ditekemena, et al., 2012; Cham and Sundby, 2005 and Babalola and Fatusi, 2009) as in the case of Nigeria.

\section{Health Care System}

Improper health care delivery without proper referral and hospital delay affects health of an individual physically, socially and mentally (Alvarez et al., 2009).

\section{Theoretical Framework}

The Functionalist Theory methodology was introduced in this research. The theory supports a country's need for a strong maternal / child health care system.

"The functionalist view's general assumptions depend on the fact that" society can be explained to itself as a whole "(Akokuwebe and Okafor, 2015). Human society is likened to classical theorists such as Comte, Spencer, and Durkheim to an organism that has distinct but interrelated components with a functional precondition for adaptation and survival. The various components (social institutions) must therefore function and adapt to each other in order for a society to survive. In their thought, the functionalist viewpoint is more refined as they try to see society as a system of interconnected and interrelated systems that form a whole, suggesting that the life of societies demands that specific aspects of the social world must operate in tandem for society to run smoothly (Akokuwebe and Okafor, 2015).

Talcott Parsons' work, which has left an indelible mark in the field of sociological thinking, is noteworthy among these contributions (Akokuwebe and Okafor, 2015). Parsons sought to develop principles that would assist in organizing the social world's perceptions. In its analysis, there are four basic requirements for any society or social system, namely Adaptation, Achieving Goals, Integration and Latency with the Acronym (AGIL). An adaptation that refers to the relationship between the social system and its surroundings is the first among the functional prerequisites. It is worth noting that social systems need to have some measures of control mechanism over their surroundings in order for society to remain alive. In order to meet the physical and social needs of people in society, food, clothing and housing must be available. The second functional prerequisite, goal achievement, refers to the need to set goals towards the direction of social events for all members of the social order.

Governments' duties are not only to set priorities, but also to assign resources to achieve them. In a nutshell, the financial or financial situation is regulated and regulated by laws and regulations adopted by the governments. Integration, the third functional requirement, refers to the pooling and mutual modification of social processes. When conflict arises, a typical example is that it is settled by the judicial system, thus not leading to the dissolution of the social system. Latency means the constant upholding of principles, norms formed in the social world, the fourth functional prerequisite. Social organisations that execute these responsibilities consist of the educational system, religion and the family (Farganis, 2003). A social system's functional prerequisites are related to social and cultural imperatives. The ambiguity of social systems under the rubric of the socialization process also exhibits the social system's integrative obligations. Meanwhile, as part of the cultural structure, principles and norms help to inspire social action.

\section{DISCUSSION OF FINDINGS}

The study shows the selected socio-economic determinants of health and its effect on maternal / child health in Nigeria, including attitudes of health care providers, economic / financial disparities, geographical (transportation problems), insecurity, marital status and age, education, gender equality, material and human capital, socio-cultural factors and delivery of health care systems. Studies have shown similar findings as determinants for the use of maternal / child health services in many countries, such as marital status, maternal and/or husband / spouse education, household financial standing, health education and socio-cultural beliefs (Simkhada et al., 2008 and Adjiwanou et al., 2018). While traditional methods were used to address the needs of maternal health care services (Simkhada et al., 2008 and Adjiwanou et al., 2018).

The results of this documentary literature review identified the most selected socio-economic determinants of maternal / child health in Nigeria, as stated by various authors and WHO; economic / financial inequity, geographical (transportation problems), insecurity, marital status and age, education, gender equality, material and human resources, socio-cultural f. The results of the findings are close to those of the Socio-economic Determinants of Health Commission of the WHO, which mainly included poor and low living conditions; unequal distribution of power and wealth within families, communities and, in particular, Nigeria overall in Africa (Marmot et al., 2008 and Munodawafa et al., 2013) Studies have documented that traditional birth attendants 'training and delivery kits from local health systems can reduce maternal / child mortality rates, especially in developing countries such as Nigeria with low-skilled professionals, poor transport physical infrastructure, poor health workers' attitude towards pregnant mothers and insecure areas (Chi et al., 2015)

In the African Union's view, most women in Nigeria face socio-cultural disparities that do not enable them to be represented politically, lack of legal rights, unequal educational opportunities and less access to reproductive health services (AU, 


\section{The Effect of Selected Socio-Economic Determinants of Health on Maternal/ Child Health in Nigeria}

2013). Most socio-economic rankings in Nigeria are correlated with casting, race, and level of education, decision-making, unequal assets management power and stigmatization. Social inferiority and discrimination usually lead to poor attitude and treatment by health care providers (Coovadia et al., 2009 and Mumtaz et al., 2018). As a result, mothers can be ignored and abused by government health workers, and the only choice will be to "die at home" instead of looking for modern health services (Gabrysch and Campbell, 2009). Health seeking conduct in many societies such as Nigeria is related to ethnicity, socio-economic religion, residence and access to transportation (Gabrysch and Campbell, 2009 and Say and Raine, 2007), women who get pregnant during adolescence mainly for economic reasons (sex for money, sex for food and clothing) and those who get pregnant frequently (within a short period of time) also $t$ Bad experiences of early or multiple causes of pregnancy, negative social, educational and economic outcomes in later life; due to pregnancies of unsafe sex or insufficient spacing. One of the methods for improving maternal and child health and reducing maternal and infant mortality is the use of contraception. With the use of contraceptives, studies have reported a reduction in maternal / child mortality (Simkhada et al., 2008; Maxwell et al., 2008 and Mochache et al., 2008)

Mechanisms for coping should be centered or carried out on the basis of the particular socio-economic determinants leading to maternal / child death. Some of the main mechanisms used to deal with the socio-economic determinants of maternal / child health in Nigeria include social participation, empowering women to improve their autonomy through education in order to create freedom to make health-related decisions (Cleland and Van, 1988 and Filippi et al., 2006). Male participation is also one of the strategies that should be implemented Some of the interventions that can help reduce maternal / child health mortality and morbidity of Nigerian women in the country are government policies on stratification for the reduction of inequality, socioeconomic security of vulnerable citizens that can help and unequal effects of disease in socio-cultural beliefs and practices. Socioeconomic determinants of maternal / child health such as poverty, lack of education, powerlessness in the distribution of resources lead to maternal malnutrition and deaths, as in the case of Ugandan women. Maternal anemia has been reported in Rio de Janeiro, Brazil, in the opinion of the World Conference on Socio-economic Determinants of Health (WC, 2011; Mochache et al., 2008; Cleland and Van, 1988 and Filippi et al., 2006), as the main cause of fatigue and poor mental concentration affecting maternal / child health and women's ultimate productivity. As a result, it also impacts infant cognitive growth, introducing learning disabilities that contribute to lower productivity by expanding the nation to poor health and poverty. A strategy for the enrichment of widely consumed foods (vegetable oil, maize and wheat flour) was developed by the National Food Fortification Program. This was accomplished by adding vitamin A to vegetable oil and a number of vitamins B-1, B-2, B-6, B-12; by infusing additives along with zinc , iron, niacin, folic acid in the milling of wheat and maize flour (Balikowa, 2011)

\section{SUMMARY OF FINDINGS}

In summary, this literature review identified numerous socio-economic determinants that consist of maternal / child health: cultural attitudes, negative perceptions of the characteristics of health care providers, health care prices, lack of transport facilities and infrastructure. The provision of maternal / child health care services has also been shown to have differences in values and behaviors. Health professionals have also had bad attitudes and inadequate care for mothers, as stated in several reports. The study also reported a lack of respect by health care providers for the privacy and confidentiality of mothers, a situation that created a barrier to maternal / child health services, especially for pregnant women.

\section{CONCLUSION/RECOMMENDATION}

In Nigeria, the national trend towards reducing maternal / child deaths has been sluggish, and some of the contributing factors to the inadequate reduction in maternal / child health are still socio-economic determinants of maternal / child health. Few studies have been carried out in Nigeria to investigate the socio-economic determinants of maternal / child health in accessing maternal health services and methods to cope with these determinants. The goal of this review study is, therefore, to benchmark findings on determinants of maternal / child health services and the common coping strategies used in Nigeria to deal with these determinants.

\section{REFERENCES}

1) Adjiwanou $V$, Bougma $M$, LeGrand T. The effect of partners' education on women's reproductive and maternal health in developing countries. Soc Sci Med. 2018;197:104-115.

2) African Union Commission. (2006) Sexual and Reproductive Health and Rights: Continental Policy Framework.

3) Addai, I. (2000), "Determinants of use of maternal-child health services in rural Ghana", Journal of Biosocial Science. 32(1):1-15.

4) Akokuwebe ME, Okafor EE. Maternal health and the implications for sustainable transformation in Nigeria. Res Humanit Soc Sci. 2015;5(6):1-3. (Google Scholar) 


\section{The Effect of Selected Socio-Economic Determinants of Health on Maternal/ Child Health in Nigeria}

5) Alvarez JL, Gil R, Hernández V, et al. Factors associated with maternal mortality in Sub-Saharan Africa: an ecological study. BMC Public Health. 2009;9:462.

6) Andersen, R.M. and Newman, J.F. (1973), "Social and individual determinants of medical care utilization in the United States", Milbank Memorial Quarterly. (51): 95-124.

7) Azevedo, M., Gwendolyn, J., Prater, S. and Lantum, D.N. (1991), "Culture, biomedicine and child mortality in Cameroon”, Social Science Medicine. 32(12): 1341-9.

8) Babalola S, Fatusi A. Determinants of use of maternal health services in Nigeria - looking beyond individual and household factors. BMC Pregnancy Childbirth. 2009;9:43.

9) Balikowa DO. Social determinants of health: Food fortification to reduce micronutrient deficiency in Uganda. World Conference on Social Determinants of Health, Rio de Janeiro, Brazil. 2011.

10) Buckley, A.D. (1976), "The secret - an idea in Yoruba medicine thought", in Loudon, J.B. (Ed.), Social Anthropology and Medicine. 421, Academic Press, London. 396-421.

11) Chi PC, Bulage $P$, Urdal H. A qualitative study exploring the determinants of maternal health service uptake in post-conflict Burundi and Northern Uganda. BMC Pregnancy and Childbirth. 2015;15:18.

12) Cleland JG, Van Ginneken JK. Maternal education and child survival in developing countries: the search for pathways of influence. Soc Sci Med. 1988;27(12):1357-1368.

13) Coovadia $H$, Jewkes $R$, Barron $P$, et al. The health and health system of South Africa: historical roots of current public health challenges. The Lancet. 2009;374(9692):817-834.

14) Celik, Y. and Hotchkiss, D.R. (2000), "The socio-economic determinants of maternal health care utilization in Turkey", Social Science \& Medicine. 50(1797-806).

15) Chakraborty, N., Islam, M.A., Chowdhury, R.I., Bari, W. and Akhter, H.H. (2003), "Determinants of the use of maternal health services in rural Bangladesh", Health Promotion International. 18(4): 327-37.

16) Cham M, Sundby J, Vangen S. Maternal mortality in the rural Gambia, a qualitative study on access to emergency obstetric care. Reproductive Health. 2005;2:3.

17) Chi PC, Urdal $\mathrm{H}$. The evolving role of traditional birth attendants in maternal health in post-conflict Africa: A qualitative study of Burundi and northern Uganda. SAGE Open Medicine. 2018;6:2050312117753631

18) Chol C, Hunter C, Debru B, et al. Stakeholders' perspectives on facilitators of and barriers to the utilisation of and access to maternal health services in Eritrea: a qualitative study. BMC pregnancy and childbirth. 2018;18(1):35.

19) Ditekemena J, Koole O, Engmann C, et al. Determinants of male involvement in maternal and child health services in subSaharan Africa: a review. Reproductive Health. 2012;9:32.

20) Ekman, B., Axelson, H., Anh Ha, D. and Nguyen, L. (2007), "Use of maternal health care services and ethnicity: a crosssectional analysis of Vietnam", available at: SSRN: http://ssrn.com/ abstract $1 / 4993713$

21) Elias T. A. (2018), Key social determinants of maternal health among African countries: a documentary review: Department of Community Medicine and Primary Health Care, Orotta School of Medicine and Dental Medicine, Eritrea

22) Elo, I.T. (1992), "Utilization of maternal health care services in Peru: the role of women's education", Health Transition Review. 2(1): 49-69.

23) Essendi H, Mills S, Fotso JC. Barriers to Formal Emergency Obstetric Care Services' Utilization. J Urban Health. 2011;88Suppl 2:S356-69.

24) Filippi V, Ronsmans $C$, Campbell O, et al. Maternal health in poor countries: the broader context and a call for action. The Lancet. 2006;368(9546):1535-1541.

25) Fosu, G.B. (1994), “Childhood morbidity and health services utilization: cross-national comparisons of user-related factors from DHS data", Social Science \& Medicine. 38 (1209-20)

26) Gabrysch S, Campbell OM. Still too far to walk: Literature review of the determinants of delivery service use. BMC Pregnancy and Childbirth. 2009;9:34

27) Gage, A.J. (2007), "Barriers to the utilization of maternal health care in rural Mali", Social Science \& Medicine. 65(8): 1666-82.

28) Gebremariam W. Do Women with Higher Autonomy Seek More Maternal and Child Health-Care? Evidence from Ethiopia and Eritrea. Stockholm Research Reports in Demography. 2007.

29) Gobindasamy, P. and Ramesh, B.M. (1997), "Maternal education and the utilization of maternal and child health services in India", National Family Health Survey Subject Reports, Number 5, International Institute for Population Sciences, Mumbai. 


\section{The Effect of Selected Socio-Economic Determinants of Health on Maternal/ Child Health in Nigeria}

30) Maclean, U. (1976), "Some aspects of sickness behavior among the Yoruba", in Louden, J.B. (Ed.), Social Anthropology and Medicine, Academic Press, London

31) Maclean, U. (1976), "Some aspects of sickness behavior among the Yoruba”, in Louden, J.B. (Ed.), Social Anthropology and Medicine, Academic Press, London.

32) Matsumura, M. and Gubhaju, B. (2001), "Women's status, household structure and the utilization of maternal health services in Nepal”, Asia Pacific Population Journal. 16, 1(23-44).

33) Mekonnen, Y. and Mekonnen, A. (2003), "Factors influencing the use of maternal health care services in Ethiopia”, Journal of Health, Population and Nutrition. 21(4): 374-82

34) Mohammadi, M.M., Hashemi, M. and Mohammadi Baghmollaei, M. (1997), "Determination of correlation of some socioeconomical factors with low birth weigh (LBW) in Bushehr Port", Journal of Bushehr University of Medical Sciences, 1(258).

35) Mojekwu JN, Ibekwe U. Maternal mortality in Nigeria:Examination of intervention methods. International Journal of Humanities and Social Science. 2012;2(20):1-15. (Google Scholar)

36) Mpembeni RN, Killewo JZ, Leshabari MT, et al. Use pattern of maternal health services and determinants of skilled care during delivery in Southern Tanzania: implications for achievement of MDG-5 targets. BMC Pregnancy Childbirth. 2007;7:29.

37) Maxwell L, Nandi A, Benedetti A, et al. Intimate partner violence and pregnancy spacing: results from a meta-analysis of individual participant time-to-event data from 29 low-and-middle-income countries. BMJ Global Health. 2008;3(1):e000304.

38) Mochache V, Lakhani A, El-Busaidy $\mathrm{H}$, et al. Pattern and determinants of contraceptive usage among women of reproductive age from the Digo community residing in Kwale, Kenya: results from a cross-sectional household survey. BMC women's health. 2008;18(1):10.

39) Mumtaz Z, Salway S, Bhatti A, et al. Addressing invisibility, inferiority, and powerlessness to achieve gains in maternal health for ultra-poor women. Lancet. 383(9922):1095-1097.

40) Munodawafa D, Sookram C, Nganda B. A strategy for addressing the key determinants of health in the African Region: WHO, Regional Office for Africa. 2013.

41) Navaneetham, K. and Dharmalingam, A. (2002), "Utilization of maternal health care services in Southern India", Social Science \& Medicine, 55(1849-69).

42) Nhindiri, P., Munjanja, S.P., Zhanda, I., Nystrom, L. and Lindmark, G. (1995), Utilization of Maternal Services in Rural Zimbabwe: A Community Base Study, Year Report, Gutu Mission Hospital, Masvingo.

43) Nwakoby, B.N. (1991), "Use of obstetric services in rural Nigeria", Journal of Royal Health. 114(132-6).

44) Nwokocha EE. Maternal crises and the role of African men:The case of Nigerian Community. African Journal of Population Studies. 2008;22(1) (Google Scholar)

45) Ochako R, Fotso J, Ikamari L, et al. Utilization of maternal health services among young women in Kenya: Insights from the Kenya. Demographic and Health Survey, 2003. BMC Pregnancy and Childbirth. 2011;11:1.

46) Okeke EC, Oluwuo SO, Azil El. Women's Perception of Males 'Involvement in Maternal Healthcare in Rivers State, Nigeria. International Journal of Health and Psychology Research. 2016;1:9-21. [Google Scholar

47) Omo-Aghoja LO, Aisien OA, Akuse JT, Bergstrom S, Okonofua FE. Maternal mortality and emergency obstetric care in Benin City, South-south Nigeria. Journal of clinical medicine and research. 2010;2(4):055-60. [Google Scholar

48) Orley, J. (1980), "Indigenous concepts of disease and their interaction with scientific medicine", in Sabben-Clare, E.E., Bradley, D.J. and Kirkwood, K. (Eds), Health in Tropical Africa during the Colonial Period, Clarendon Press, Oxford. 12737.

49) Raghupathy, S. (1996), "Education and the use of maternal health care in Thailand", Social Science \& Medicine. 43(4): 459-71.

50) Rahaman, M.M., Aziz, K.M., Munshi, M.H., Patwari, Y. and Rahman, M. (1982), "A diarrhea clinic in rural Bangladesh: influence of distance, age and sex on attendance and diarrheal mortality", American Journal of Public Health. (72): 11248.

51) Say L, Raine R. A systematic review of inequalities in the use of maternal health care in developing countries: examining the scale of the problem and the importance of context. Bull World Health Organ. 2007;85(10):812-819.

52) Stock, R. (1983), "Distance and utilisation of health facilities in rural Nigeria", Social Science \& Medicine, 17(63-570).

53) Samb OM, Ridde V. The impact of free healthcare on women's capability: A qualitative study in rural Burkina Faso. Soc Sci Med. 2018;197:9-16 
The Effect of Selected Socio-Economic Determinants of Health on Maternal/ Child Health in Nigeria

54) Van den Heuvel, D.A., de Mey, W.G., Buddingh, H. and Bots, M.L. (1999), "Use of maternal care in a rural area of Zimbabwe: a population-based study", Acta Obstet Gynecol Scand. 78(838-46).

55) World Health Organization (1994), Antenatal Care: Report of a Technical Working Group, World Health Organization, Geneva, 31 October-4 November

56) World Health Organization. Fact sheets. 2018 (Google Scholar) 